\title{
Techno-economic evaluation of a ventilation system assisted with exhaust air heat recovery, electrical heater and solar energy
}

\author{
Gamze Ozyogurtcu ${ }^{\mathrm{a}}$, Moghtada Mobedi ${ }^{\mathrm{a}, *}$, Baris Ozerdem $^{\mathrm{b}}$ \\ a Department of Mechanical Engineering, Izmir Institute of Technology, Urla 35430, Izmir, Turkey \\ ${ }^{\mathrm{b}}$ Department of Energy Systems Engineering, Bahcesehir University, Besiktas 34353, Istanbul, Turkey
}

\section{A R T I C L E I N F O}

\section{Article history:}

Received 22 January 2013

Received in revised form 4 November 2013

Accepted 23 December 2013

\section{Keywords:}

Ventilation system

Solar energy in buildings

Economical analysis

\begin{abstract}
A B S T R A C T
The energy consumed to condition fresh air is considerable, particularly for the buildings such as cinema, theatre or gymnasium saloons. The aim of the present study is to design a ventilation system assisted with exhaust air heat recovery unit, electrical heater and stored solar energy, then to make an economical analysis based on life cycle cost (LCC) to find out its payback period. The system is able to recover thermal energy of exhaust air, store solar energy during the sunlight period and utilize it in the period between 17:00 and 24:00 h. The transient behaviour of the system is simulated by the TRNSYS 16 software for winter period from 1 st of November to 31 st of March for Izmir city of Turkey. The obtained results show that the suggested ventilation system reduces energy consumption by $86 \%$ compared to the conventional ventilation system in which an electrical heater is used. The payback period of the suggested system is found to be 5 years and 8 months which is a promising result in favour of the solar energy usage in building ventilation systems.
\end{abstract}

(c) 2013 Elsevier B.V. All rights reserved.

\section{Introduction}

Many people live, work, study or spend their leisure time in buildings having heating, ventilation and air conditioning (HVAC) system that provides hot/cold, fresh, and clean indoor air at proper temperature and humidity levels. In this manner, the ventilation process plays an important role on improving indoor air quality. If fresh air could not be supplied into the buildings, harmful pollutants such as $\mathrm{CO}_{2}$ accumulate in indoor spaces. Fresh air cannot be supplied to the building directly, in general. An HVAC system should heat or cool fresh air first, and then supplies it into the indoor space to prevent destroying of indoor thermal comfort. Due to its costly operation, some energy saving strategies can be established for heating or cooling processes of fresh outdoor air. Nowadays, the usage of heat recovery and energy storage is an effective trend. Due to limited fossil fuel resources and their hazardous environmental impacts, utilization of renewable energy resources becomes one of the most important research areas for HVAC systems in recent decades. Solar energy is a reliable and convenient energy resource; however, the variability and discontinuity of solar radiation cause serious difficulties on its applicability. Thermal energy storage systems have been developed to overcome the problem of solar radiation discontinuity. Thermal energy storage systems can store solar energy during peak periods to utilize it during the lower

\footnotetext{
* Corresponding author. Tel.: +90 232750 6709; fax: +90 2327506701

E-mail address: moghtadamobedi@iyte.edu.tr (M. Mobedi).
}

solar radiation or solar off periods. Solar energy can be stored by sensible, latent or chemical storage systems. Among them, the sensible energy storage may be the simplest and the most convenient choice for practical applications.

Studies on the use of thermal sensible energy storage for an HVAC system can be found in the related literature. The storage medium is mostly water, natural soil, special soils (i.e. gravel, grit or sand) or a combination of these materials. Solar energy is stored in these media and used later on. Literature survey shows that seasonal thermal storage is preferred in the most of studies. Ozyogurtcu [1] showed that the use of solar assisted ventilation system with heat recovery unit reduces considerably ventilation energy consumption compared with conventional ventilation system in which only an electrical heater operates. Kroll and Ziegler [2] investigated the use of ground heat storage and evacuated tube solar collectors for meeting the annual heating demand of family-sized houses. In their seasonal storage system study, soil is used as a storage material. They found that the system with a ground heat storage and high quality evacuated tube collector is able to supply an essential part of heat demand of a family-sized houses. Simons and Firth [3] performed a study on life cycle assessment of a $100 \%$ solar fraction thermal supply to a European apartment building by using water-based seasonal sensible heat storage. They compared $100 \%$ solar heating system recently installed in a Swiss apartment building with five alternative heating systems on the basis of life cycle assessment. Terziotti et al. [4] studied on the modelling seasonal solar thermal energy storage (SSTES) in a large urban residential building using the software called TRNSYS 16. Their seasonal solar 
thermal energy storage system used two closed fluid (water) loops. One loop ran through solar collectors to heat the fluid, then into coils inside the storage medium. Fehrm et al. [5] studied on exhaust air heat recovery units in buildings. They investigated systems use exhaust air as a source of heat for the appliances. Yumrutas and Ünsal [6] performed an energy analysis and modelling of a solar assisted house heating system with a heat pump and an underground energy storage tank. Results of their study indicated that an operational time span of 5-7 years would be necessary before the system could attain an annually periodic operating condition. Calise et al. [7] performed a study on transient analysis and energy optimization of solar heating and cooling systems in various configurations. The simulation model was developed by using the TRNSYS software, and included the analysis of the dynamic behaviour of the building in which the solar heating and cooling systems were supposed to be installed. The obtained results of the study analyzed on monthly and weekly basis were encouraging. Ortiz et al. [8] modelled a solar-assisted HVAC system with thermal storage for the Mechanical Engineering Department building of the University of New Mexico in order to predict performance and optimize control parameters. They found that the solar assist could account meet for over $90 \%$ of the total heating requirements, if certain energy conservation strategies are adopted. Further information on the utilization of heat of exhaust air and solar energy in the buildings for heating purpose can be found in Refs. [9-11].

For economic analysis of HVAC system, the study of Kizilkan et al. [12] on thermoeconomic optimization of a $\mathrm{LiBr}$ absorption refrigeration system can be mentioned. The thermoeconomic optimization study was performed in order to determine the optimum operating temperatures and parameters of a $\mathrm{LiBr}$ absorption refrigeration system. Ahmadi et al. [13] performed a study on the exergo-environmental analysis of an integrated organic Rankine cycle for trigeneration system. Environmental impact assessment, energy and exergy analyses were carried for a trigeneration system consists of a gas turbine cycle, an organic Rankine cycle, a single-effect absorption chiller and a domestic water heater. Further information on thermo-economic analysis of different systems such as polygeneration systems, central air conditioners and power plants can be found in Refs. [14-16].

The aim of the present study is to suggest a ventilation system assisted by solar energy, heat recovery unit, and an auxiliary electrical heater. The application areas of the proposed system are theatres, cinemas, gymnasium saloons, shopping centres and other spaces which require high rate of fresh air due to peak occupation time between 17:00 and 24:00 h. The hourly energy analysis of the suggested system and traditional system, operating only with an electrical heater, is performed by using TRNSYS 16 software for winter period from 1 st of November to 31st of March for Izmir city of Turkey. The total energy consumption for both systems is determined and then compared for the considered period. The obtained results are presented and discussed via graphics. Furthermore, the initial investment and maintenance costs of both traditional and suggested systems are determined based on the prices in Turkish HVAC market available in 2013 in order to perform an economical analysis for both systems. The aim of economical analysis is to find out payback period of the suggested system.

Based on the above literature survey, it is observed that no study on the use of both heat of exhaust air and stored solar energy for heating of fresh air for ventilation purpose in the buildings was performed. The proposed system is an innovative system which can reduce the energy consumptions in the buildings, considerably. Furthermore, the energy and economical evaluations are performed for this innovated system to investigate applicability of the system, practically. Hence, the results of the present study are new and original.

\section{The traditional and proposed innovative ventilation systems}

Both the traditional and suggested ventilation systems are analyzed in the present study. The main components of traditional ventilation system are supply and return fans, an electrical heater and a simple automation system as shown in Fig. 1(a). The main components of the suggested system are supply and return fans, an electrical heater, a heat recovery unit and a solar energy storage system as shown in Fig. 1(b). The solar energy storage system mainly consists of an evacuated tube solar collector, a sensible heat storage tank with heating coil and circulation pumps. There are two separate loops in the solar energy system. In the first loop, water circulates between solar collector and sensible storage tank by a circulation pump named as pump \#1. In the second loop, the water is circulated between tank and heating coil by another circulation pump named as pump \#2. Solar collector is used to increase the water temperature. The water at high temperature enters to the sensible storage tank and transfers heat of circulated water to the storage tank water. Then, the water leaves storage tank at lower temperature. It enters to the pump \#1 and becomes pressurized to be circulated in the loop \#1. The control of pump \#1 is done by a differential temperature controller. It receives average temperature of the water storage tank and outlet temperature of the solar collector. If the temperature inside the storage tank is greater than the solar collector outlet temperature, a signal is sent to pump \#1 for stopping. When sun rises, the solar collector outlet temperature becomes greater than the temperature of storage tank, operated at night period. During sunset, the collector outlet temperature becomes less than the storage tank temperature. Hence, a signal is sent to pump \#1 to stop circulation. By this way, the temperature of storage tank increases during the sun light period. Our observation showed that the temperature of water at outlet of solar collector may exceed $100{ }^{\circ} \mathrm{C}$ in warm days during winter period. That is why a temperature controller is adapted to the system for controlling outlet water temperature of solar collector for safety reason. If the temperature of solar collector exceeds $90^{\circ} \mathrm{C}$, the pump \#1 stops the water circulation.

The operation of loop \#2 is arranged by a time controller. It operates from 17:00 to 24:00 $\mathrm{h}$ which is the operation period of the ventilation system. At 17:00 h, the time controller sends a signal to pump \#2 and water is circulated through loop \#2. The pressurized water leaves the pump \#2 and enters to the storage tank. Then, the water leaves storage tank at higher temperature and flows towards heating coil. Heat is transferred from the hot water that leaves the storage tank to the air via the heating coil. On the other hand, fresh air, which should be supplied to the space, is preheated by the heat recovery unit. The temperature of fresh air is increased by the energy of exhaust air. Then, the fresh air is passed through the coil heat exchanger connected to the solar energy storage system. Finally, the fresh air flows towards the electrical heater. If the fresh air temperature is less than $22^{\circ} \mathrm{C}$, the electrical heater automatically operates and increases the fresh air temperature to $22^{\circ} \mathrm{C}$. After 24:00 h, the supply and return fans are switched off automatically. By this way, the solar energy stored in the storage tank during day period is used to heat fresh air required from 17:00 to 24:00 h. The study is performed at air flow rate of $1000 \mathrm{~m}^{3} / \mathrm{h}$. The solar collector, storage tank, heat recovery unit and heating coil are the main components of the proposed system. For the studied systems, the optimal design of heat recovery unit and heating coil is performed by HVAC manufacturers. The commercial programs developed by manufacturers are used to determine the optimal design of heat recovery unit and coils for the given operational conditions. Based on the specified air flow rate, double core aluminium plate type heat recovery unit, each has size of $500 \mathrm{~mm} \times 500 \mathrm{~mm} \times 500 \mathrm{~mm}$ and pressure drop of $100 \mathrm{~Pa}$, is chosen as the optimal design for 
(a)
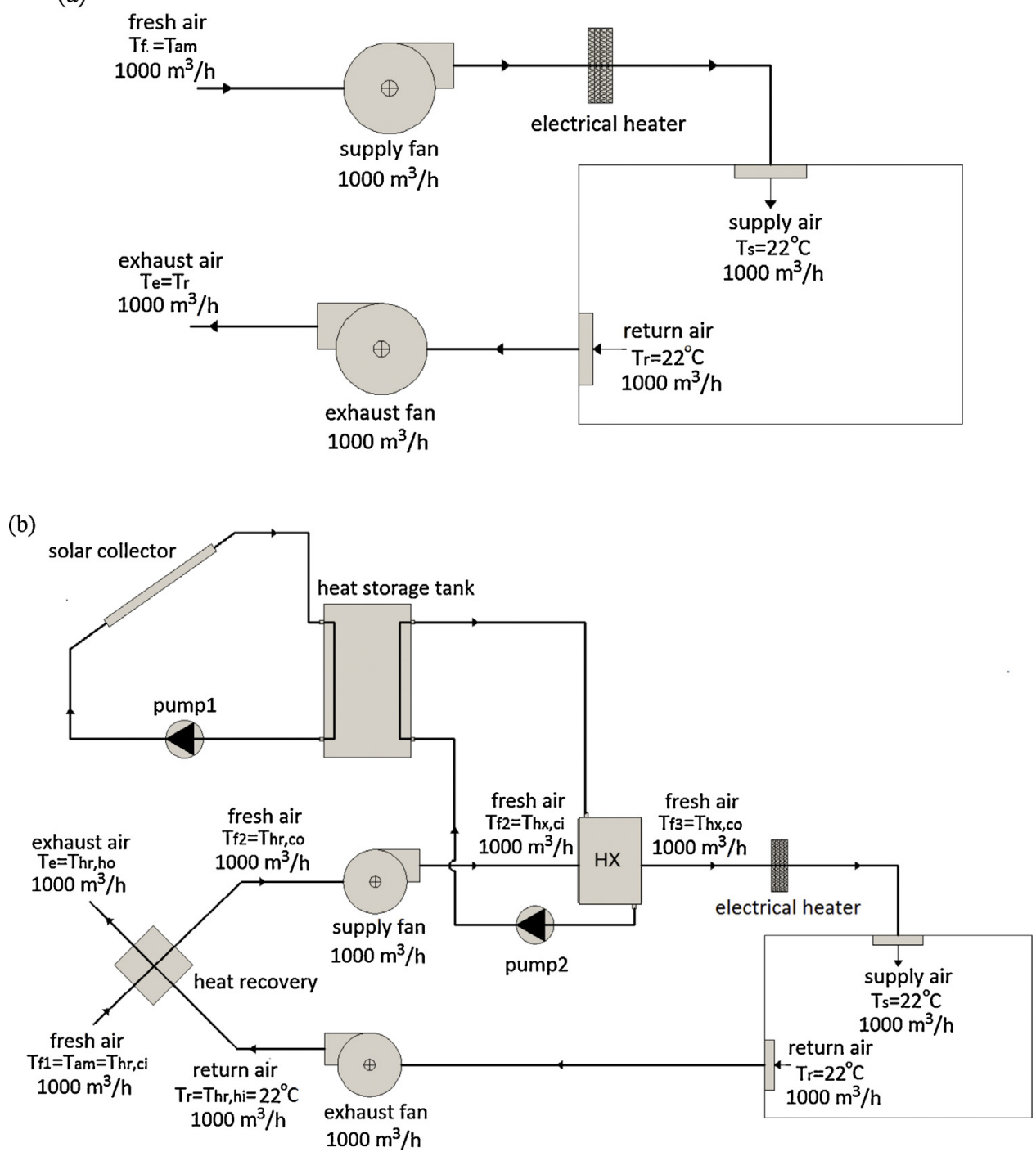

Fig. 1. Schematic view of the studied ventilation systems: (a) traditional system and (b) suggested system.

heat recovering of exhaust air. Similarly, a coil type heat exchanger with size of approximately $470 \mathrm{~mm} \times 390 \mathrm{~mm} \times 90 \mathrm{~mm}$, heat transfer area of $6.67 \mathrm{~m}^{2}$, pressure drop of $84.8 \mathrm{~Pa}$ for air side and $1.76 \mathrm{kPa}$ for water side is optimal design for heating of supply air. The main difficulty for the application of the system is the area of solar collector which affects the volume of the storage tank. That is why a study, presented in next section, is performed to find a relation between the solar collector area and the required storage tank volume

\section{Methodology for techno-economic analysis}

TRNSYS 16 is a commercially available software used to simulate transient behaviour of an HVAC system and analyze its energy consumption. TRNSYS 16 has a modular structure and it has its own description language for system components and their connections, as well. It provides possibility for a user to define a specific component, establish a specified system or connect the components.

In the present study, the main input of the simulation program is the weather data of Izmir city of Turkey submitted with module type of 109. Furthermore, each module of TRNSYS 16 simulates a component of the system and it has its own input design parameters. For instance, in order to simulate a circulation pump, parameters such as maximum flow rate, fluid specific heat, maximum power, conversion coefficient and power coefficient should be assigned. These values are received from HVAC manufacturers of Turkey for the given operation condition. In this study, it is aimed to design and investigate a new innovative system by using conventional components available in HVAC market rather than to design new components. Thus, the types of employed components in the suggested innovative system are selected by cooperation with HVAC consulting and manufacturing companies in Turkey. The technical data entered to TRNSYS 16 program for the components are data of the optimal available components in HVAC market of Turkey. The thermodynamic modelling of each employed component and details about the employed models for simulation of the solar collector, storage tank, heat exchanger and pump can be found in Refs. [18,19].

The employed system components are weather data, solar collector, storage tank, circulation pumps, heating coil, heat recovery unit, supply and return fans, electrical heater, temperature and time controllers, integrator and plotter. Fig. 2(a) and (b) shows the schematic view of the systems designed in TRNSYS 16 software. As it was mentioned before, the weather data used in the system is type 109 and it serves the main purpose of reading weather data at regular time intervals from a data file. For this study, weather 
(a)

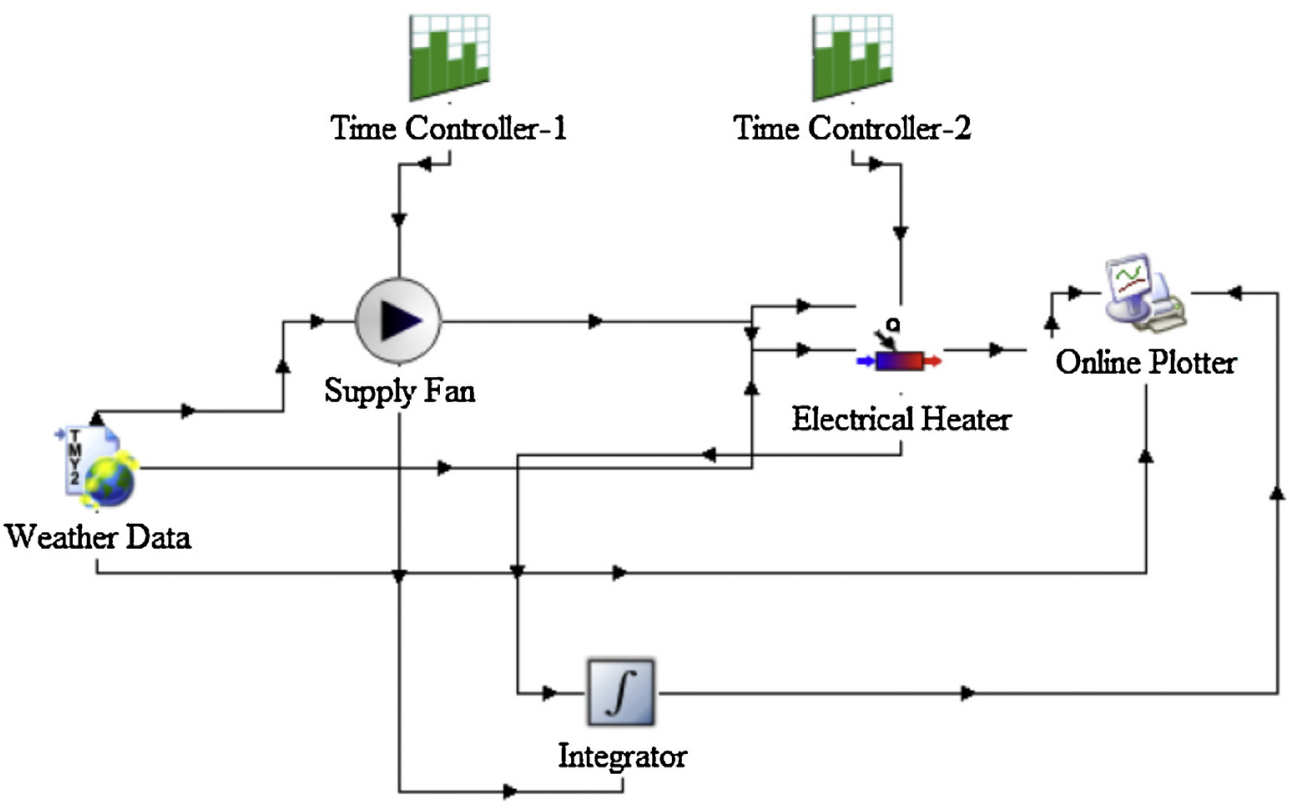

(b)

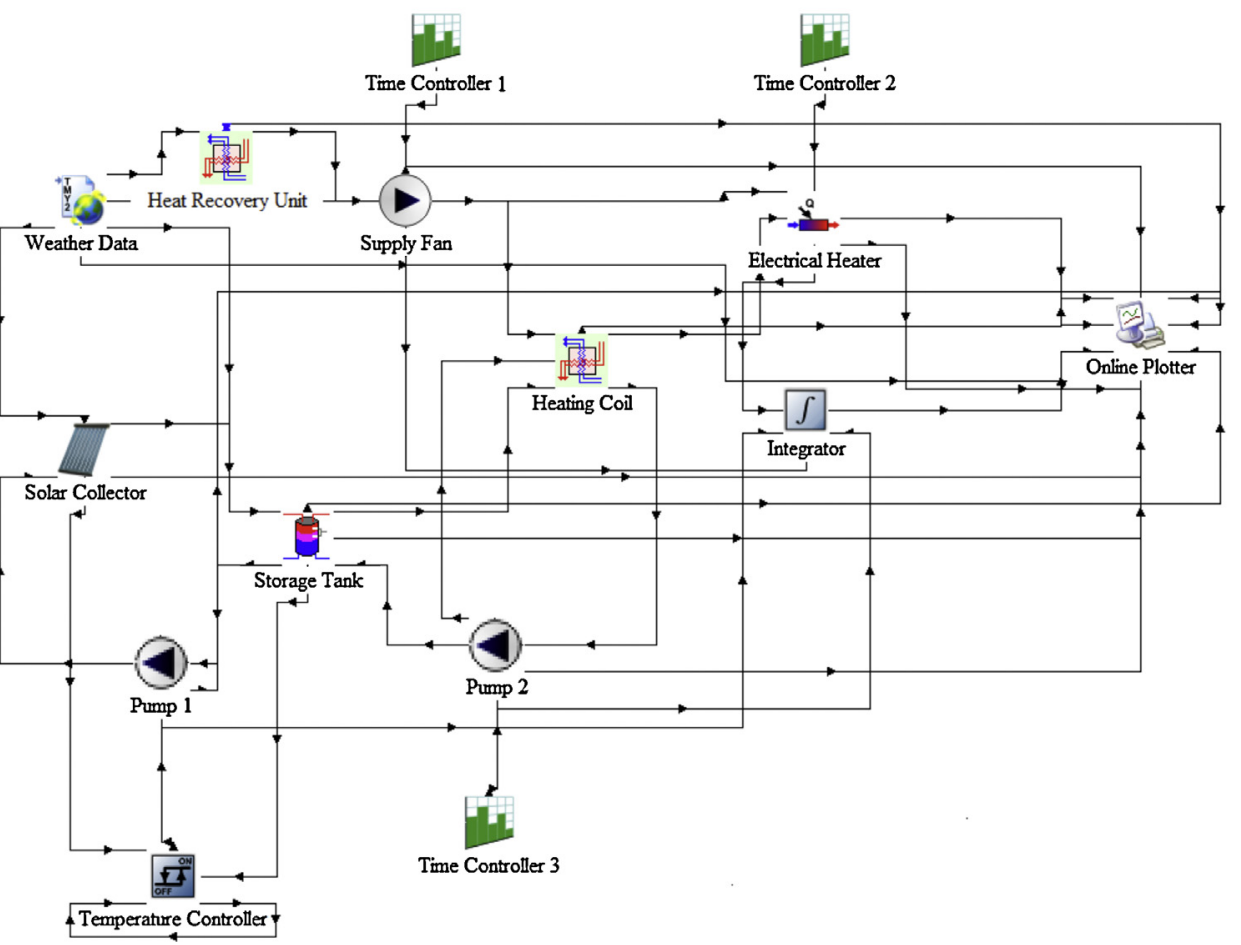

Fig. 2. View of systems designed by TRNSYS default components: (a) traditional system and (b) proposed system.

data of Izmir city of Turkey is used. The employed solar collector is type 71. This type of solar collector models an evacuated tube solar collector. The storage tank is type 60 and models a stratified liquid storage tank. This tank is vertically cylindrical and has two inlet and outlet ports. The circulation pumps in this study are single speed ones. In single speed pump applications, water flow rate and electrical consumption are constant. These pumps are referred as type $3 \mathrm{~b}$. The heating coil and heat recovery unit used in the system are zero capacitance sensible heat exchangers and they are modelled in various configurations. In the present study, a cross flow heat exchanger is used with both hot (source) and cold (load) sides which are unmixed. This model is type 5e in the TRNSYS 16 library. The considered fans in this study are single speed. In single speed fan applications, similar to the single speed pump, air flow rate and fan electrical consumption are constant. These fans are represented by type 3c. Type 6 is used as an auxiliary electrical heater. The temperature controller used in this study is an on/off differential controller. It generates a control function which could have a value of 1 or 0 , where 1 means on and 0 means off mode. The value of the control signal is chosen as a function of difference between upper and lower temperatures. This controller is used in the loop \#1 in order to control the pump \#1. The reference temperatures are the average temperature of the storage tank and temperature of water at outlet of solar collector. The dead band temperature differences are assumed zero. This model is referred as type $2 \mathrm{~b}$ of the TRNSYS library. 
The time controller (type 14h) is a time dependent forcing function which has a behaviour characterized by a repeated pattern. The pattern of the forcing function is established by a set of discrete data points indicating the value of the function at various times throughout the cycle. The integrator is component named type 24 and integrates a series of quantities over a period of time. Each quantity integrator could have up to maximum 500 inputs. The online plotter component is used to display results of the selected system variables while the simulation is progressing. Type 65a also collects the simulation results data in a file.

The life cycle cost (LCC) analysis is an essential process and an effective tool for evaluating the initial investment and future costs for a project over its entire life span. The usage of LCC analysis leads investors to more rational purchase decisions. LCC analysis is composed of three main components. The first component is the cost which can be break into two expenses, namely, initial and future costs. Future costs also can be categorized as one-time, and recurring costs. The second component of LCC analysis is time which corresponds to the expected life span of a project. This life span period also can be break into two phases as planning and construction period, and service period. The third component is the discount rate which reflects the time value of money. The discount rate gives the present value of future costs, as well. The LCC analysis is an important aid in developing the costs, and revenues or operating expenses structure for a project. Most engineering projects can be accomplished by more than one feasible design alternative. In practice, investors consider the acceptable alternative that requires the least investment of capital. The additional investment can be considered only for capacity increase, quality increase, revenue increase or operating expenses decrease. Therefore, before additional money is invested, it must be shown that extra benefits can be obtained out of this investment. In this study, the net present value (NPV) method, which is one of the valid methods for the economical comparison of alternative ventilation system configurations, is used. By using this approach, the cost and benefit of each option are converted into present value and the highest NPV is chosen as a preferred option among the alternatives. Mathematical expression of NPV value can be given as follows:

$\mathrm{NPV}=\sum_{n=k+1}^{t} \frac{B_{n}}{(1+i)^{n}}-\sum_{n=0}^{k} \frac{C_{n}}{(1+i)^{n}}$

where $B_{n}$ and $C_{n}$ are benefit and cost values corresponding to systems' life span ( $n$ in years), respectively. The annual interest rate is represented as $(i)$. The cost parameter includes the capital investment of the whole ventilation system, and maintenance expenses over the life span of the system. The benefit parameter includes decreased operating expenses which correspond to reduction of total electricity usage cost over the life span, in this study. In order to make the economical analysis, energy values in the unit of MJ are converted into the unit of $\mathrm{kWh}$ by using the proportionality factor of 3.6. Payback analysis is another extension of the NPV. There is a logical linkage between payback and breakeven analysis. Payback period is the estimated time which will take for the estimated net economical benefits to recover the initial investment difference and stated annual interest rate. For a uniform net cash flow or benefit series which is the case in this study, the payback period, $n_{p}$, can be given as:

$n_{p}=\frac{P}{\mathrm{NCF}}$

where $P$ is the initial investment difference between the alternatives, and NCF is net cash benefit for each year.

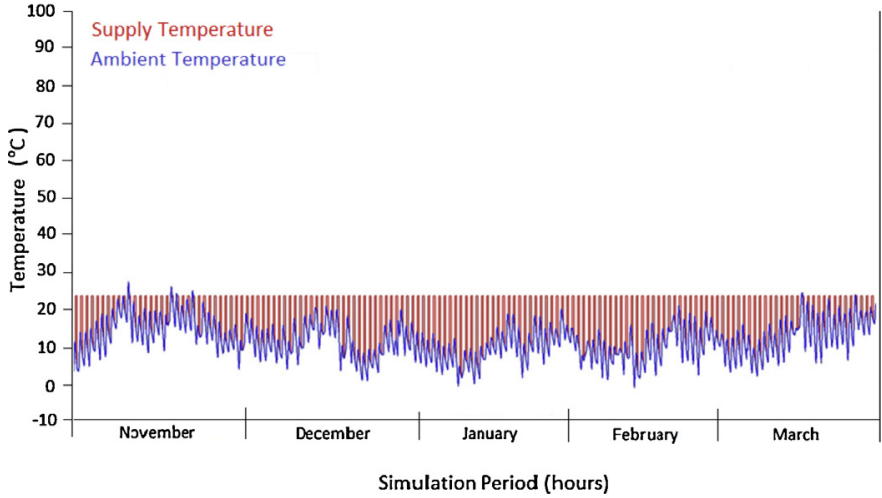

Fig. 3. The change of ambient and air supply temperatures during the studied period for a traditional system.

\section{Results and discussion}

Firstly, the changes of ambient and outlet temperatures of traditional system for the whole studied period are shown in Fig. 3. As seen, the ambient temperature is below $22^{\circ} \mathrm{C}$ in the considered period, and electrical heater increases fresh air temperature to $22^{\circ} \mathrm{C}$, as well. During the off-period of the system, the fresh air temperature is equal to ambient temperature, since the electrical heater and fans are stopped.

Our simulation study shows that the volume of storage tank and solar collector area play an important role on energy consumption and investment cost. That is why an attempt is done to optimize the volume of the storage tank and area of solar collector. In order to investigate the effect of solar collector area and storage tank volume on the energy consumption of electrical heater, 54 different cases are considered and simulations are performed by changing solar collector area between 5 and $50 \mathrm{~m}^{2}$, and storage tank volume between 0.5 and $8.0 \mathrm{~m}^{3}$. It is clearly seen from Fig. 4 that the larger solar collector area decreases the total electrical heater energy consumption for the studied period. The decreasing rate of total energy consumption of electrical heater changes with the solar collector area. For smaller solar collector area (e.g. $5 \mathrm{~m}^{2}$ ), the increase of solar collector area reduces the total consumption of electrical heater energy, drastically. Comparatively, the increase of solar collector area does not change total electrical heater energy consumption for large solar collector area (e.g. $30 \mathrm{~m}^{2}$ ). For each solar collector area, there is an optimal storage tank volume in which the minimum electricity is consumed. The optimal point of storage tank changes with the solar collector area. For a solar collector area of $5 \mathrm{~m}^{2}$, the optimal storage tank volume is $1 \mathrm{~m}^{3}$, however this value increases

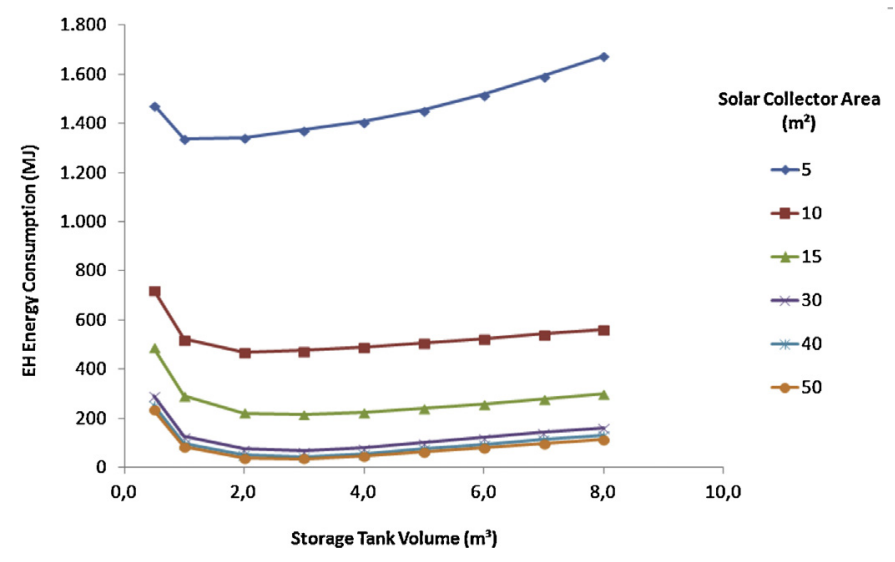

Fig. 4. Optimization of solar collector and storage tank. 


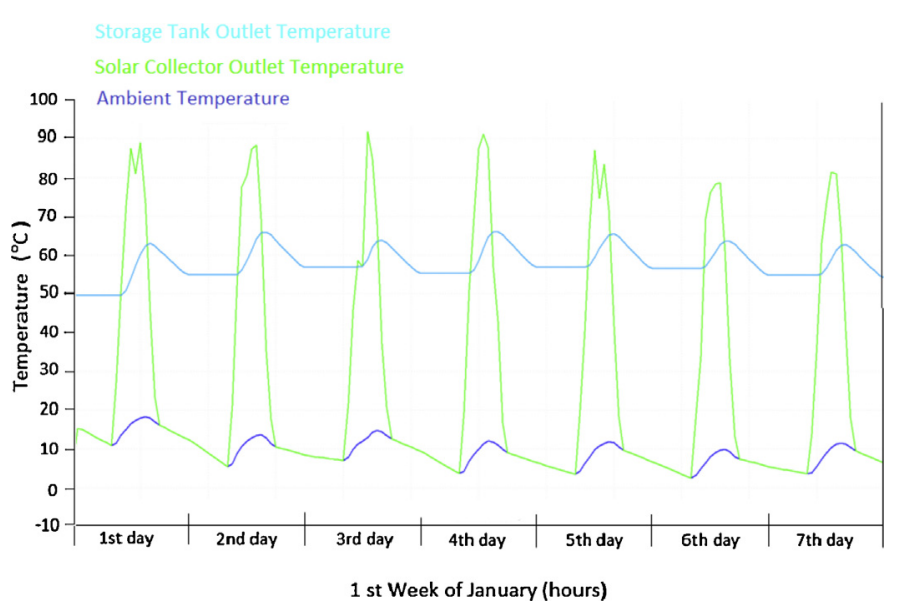

Fig. 5. The change of ambient, solar collector outlet and storage tank outlet water temperatures with time for the period of January first week.

to $3 \mathrm{~m}^{3}$ for the solar collector area of $40 \mathrm{~m}^{2}$. In this study, the simulation results of a system with $2 \mathrm{~m}^{3}$ storage tank volume and $30 \mathrm{~m}^{2}$ solar collector area are presented. Before presenting the results for whole period between $1 \mathrm{st}$ of November and 31st of March, it might be useful to perform a discussion on the graphics presenting results only for the first week of January.

Fig. 5 shows the changes of ambient, solar collector outlet, and storage tank outlet temperatures over time for the period of the first week of January for the proposed system. For a system with $30 \mathrm{~m}^{2}$ solar collector area and $2 \mathrm{~m}^{3}$ storage tank water volume, it is seen that solar collector water outlet temperature increases approximately to $90^{\circ} \mathrm{C}$ due to the effect of irradiance, whereas the water temperature in the storage tank outlet is around $65^{\circ} \mathrm{C}$. The water outlet temperature in the storage tank increases during the day, and then drops during the period of between 17:00 and 24:00 h. Fig. 6 shows the change of ambient, heat recovery unit air outlet, and heating coil air outlet temperatures over time for the period of the first week of January. It is seen that the energy stored in the storage tank increases air outlet temperature of heating coil approximately by $7^{\circ} \mathrm{C}$ between $17: 00$ and $24: 00 \mathrm{~h}$. Fig. 7 shows the changes of ambient, heating coil outlet, and electrical heater outlet air temperatures over time for the same period of time. The changes of electrical heater outlet temperature and heating coil outlet temperature overlap indicating that the electrical heater does not operate in the first week of January and the stored solar energy is sufficient to heat fresh air for indoor ventilation. Finally, Fig. 8 shows the changes of ambient, heat recovery unit outlet, heating coil outlet, and electrical heater outlet air temperatures over time for the

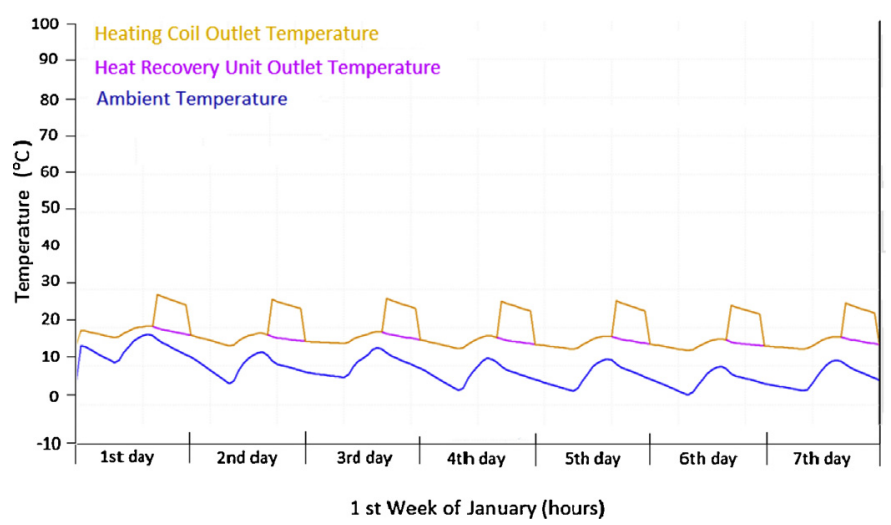

Fig. 6. The change of ambient, heat recovery unit and heating coil air outlet temperatures with time for the period of January first week.

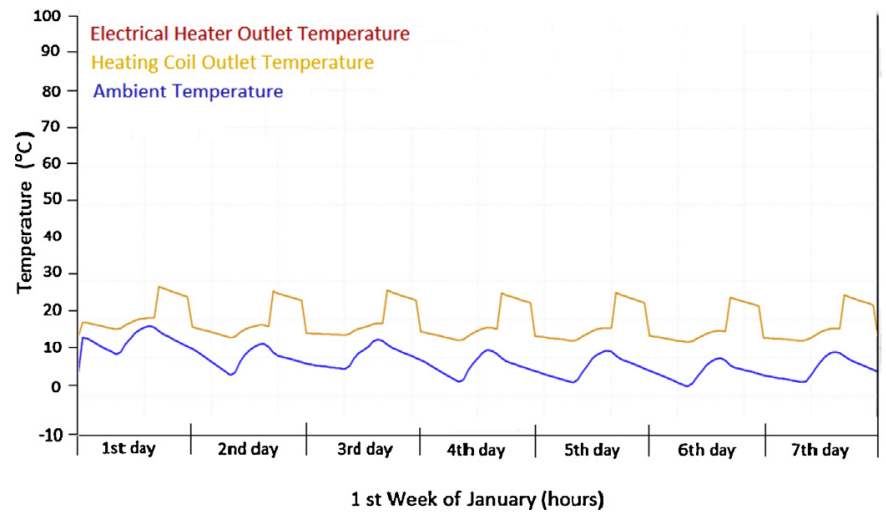

Fig. 7. The change of ambient, heating coil and electrical heater outlet air temperatures with time for the period of January first week.

whole simulation period which refers between 1st of November and 31st of March for Izmir city of Turkey. It is remarkable that the electrical heater operates only a few times during simulation period since the heating coil outlet temperature is usually greater than $22^{\circ} \mathrm{C}$.

The total energy consumption of electrical heater for the traditional and proposed systems with $30 \mathrm{~m}^{2}$ solar collector area and $2 \mathrm{~m}^{3}$ storage tank volume can be calculated by integration of instantaneous electrical heater energy consumption between 1st of November and 31st of March. The consumptions of the supply and return fans should be added to the calculated value. The rated power values of the supply and return fans are 180 and $370 \mathrm{~W}$ for traditional and proposed systems, respectively. The integration of this power consumption for the whole operating period yields totally 1370 and $2816 \mathrm{MJ}$ for supply and returns fans, respectively. The power values of pump \#1 and pump \#2 are 27 and $18 \mathrm{~W}$ for the proposed system, respectively. The integration of this power consumption for the whole operating period yields totally $132 \mathrm{MJ}$. The total energy consumptions of the traditional and proposed systems are $15,115 \mathrm{MJ}$ and $3023 \mathrm{MJ}$, respectively. The difference in energy consumption between the two systems is $12,092 \mathrm{MJ}$. In addition to this value, some amount of energy is also gained by reducing heating load of the building if a solar assisted system is used since the supply temperature becomes more than $22^{\circ} \mathrm{C}$ time by time. This means another $6577 \mathrm{MJ}$ of energy can be saved. As a result, the total energy consumption saving becomes $18,669 \mathrm{MJ}$. The comparison between the studied system and the practical system shows that the use of proposed system reduces energy consumption by $86 \%$.

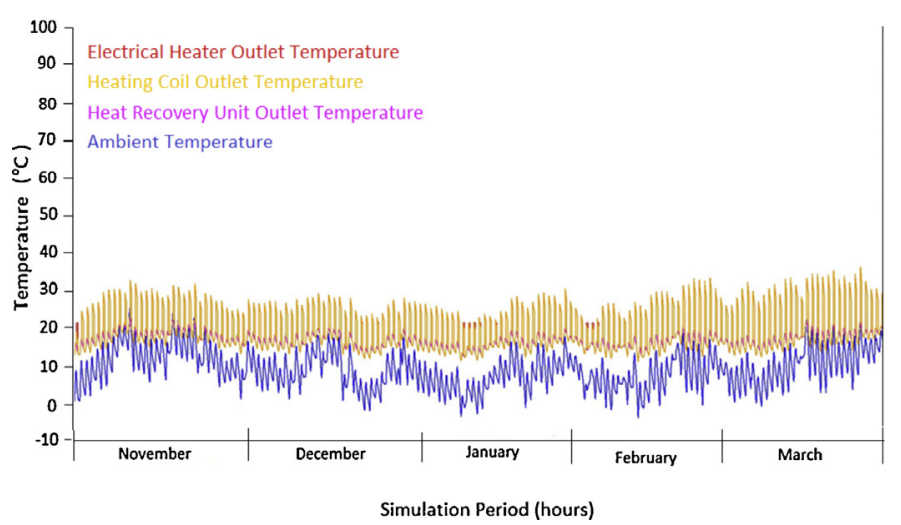

Fig. 8. The change of ambient, heat recovery unit, heating coil and electrical heater outlet air temperatures with time for the period of 1 st of November and 31st of March. 
The both considered systems' life spans are assumed as 20 years. Determination of the annual interest rate $(i)$ is important in the NPV calculations. Since Turkey is the candidate of European Union, Euro Area inflation rate averaged 2.24\% from 1991 to 2013, reaching an all-time high of 5\% [17]. In order to stay in the secured range in the study, the annual interest rate assumed as $5 \%$ throughout the systems' life span. The average Euro Area inflation rate which is $2.24 \%$ is also applied to the electricity utilization price throughout the systems' life span, as well. As a result, the electricity utilization price assumed to be changed between 0.15 and $0.23 € / \mathrm{kWh}$.

The payments determining the costs are taken due at the end of the considered period. The salvage value of the ventilation systems is not taken into consideration during the calculations. The highest NPV is chosen as the most preferred ventilation system configuration. In other words, NPVs between the systems must be as much as higher in favour of the selected one. Hence, the extra benefits obtained by investing the additional capital become justified.

Based on the prices in Turkish HVAC market available in the year 2013 , the solar assisted ventilation system costs $6510 €$, whereas conventional ventilation system costs $1850 €$, including installation and maintenance costs. Hence, in the beginning, the investment difference between the ventilation systems is $4660 €$ in favour of the conventional ventilation system. But, contrary to this, the cost of total energy saved is calculated as $14,864 €$ in favour of solar assisted ventilation system, during the life long period of usage. This concludes the net present value of the solar assisted ventilation system to be as $10,204 €$. As a result, the payback period of solar assisted ventilation system is found as 5 years and 8.2 months, exactly.

\section{Conclusions}

A theoretical study is performed on economical analysis of a heat recovery and solar assisted HVAC system used for ventilation of a space. The exhaust air is passed through a heat recovery unit and preheated, then it is heated by thermal energy of a solar collector stored in a tank and finally its temperature rises to $22^{\circ} \mathrm{C}$ by using an electrical heater, if it is required. The study is performed by TRNSYS 16 code and following remarks are concluded:

- The suggested system not only can provide fresh air at $22^{\circ} \mathrm{C}$ even without using electrical heater (for most period of winter) but also it reduces heating load of the space since, in most of the winter period, by supplying fresh air with temperature above $22^{\circ} \mathrm{C}$.

- The simulation results showed that the volume of storage tank as $2 \mathrm{~m}^{3}$ and the solar collector area of $30 \mathrm{~m}^{2}$ are the optimal values for supplying $1000 \mathrm{~m}^{3} / \mathrm{h}$ fresh air for a space in Izmir city.

- The difference in energy consumption between conventional and the suggested ventilation system from 1 st of November to $31 \mathrm{st}$ of March is $18,669 \mathrm{MJ}$, and the suggested ventilation system reduces energy consumption by $86 \%$.
- If the electricity utility price is assumed changing according to the inflation rate averaged $2.24 \%$ starting from $0.15 € / \mathrm{kW}$ h throughout the systems' life span, the payback period of solar assisted ventilation system becomes 5 years and 8.2 months, exactly.

It order to decrease the payback period of solar assisted ventilation systems, the number of consumers using the suggested system should be increased. This might cause the decrease of investment cost. Hence, solar energy assistance in ventilation systems could be used widely, especially at the locations getting higher irradiance.

\section{References}

[1] G. Ozyogurtcu, A study on combination for electrical heater, exhaust heat recovery unit and solar energy assisted system for building ventilation (M.Sc. thesis), Izmir Institute of Technology, 2012

[2] A.J. Kroll, F. Ziegler, The use of ground heat storages and evacuated tube solar collectors for meeting the annual heating demand of family-sized houses, Solar Energy 85 (2011) 2611-2621

[3] A. Simons, S.K. Firth, Life-cycle assessment of a 00\% solar fraction thermal supply to a European apartment building using water-based sensible heat storage, Energy and Buildings 43 (2011) 1231-1240.

[4] L.T. Terziotti, M.L. Sweet, J.T. McLeskey Jr., Modeling seasonal solar thermal energy storage in a large urban residential building using TRNSYS 16, Energy and Buildings 45 (2012) 28-31.

[5] M. Fehrm, W. Reiners, M. Ungemach, Exhaust air heat recovery in buildings, International Journal of Refrigeration 25 (2012) 439-449.

[6] R. Yumrutaş, M. Ünsal, Energy analysis and modeling of a solar assisted house heating system with a heat pump and an underground energy storage tank, Solar Energy 86 (2012) 983-993.

[7] F. Calise, M. Dentice d'Acadia, A. Palombo, Transient analysis and energy optimization of solar heating and cooling system in various configurations, Solar Energy 84 (2010) 432-449.

[8] M. Ortiz, H. Barsun, H. He, P. Vorobieff, A. Mammoli, Modeling of a solar-assisted HVAC system with thermal storage, Energy and Buildings 42 (2010) 500-509.

[9] R. Spur, D. Fiala, D. Nevrala, D. Probert, Influence of the domestic hot-water daily draw-off profile on the performance of a hot-water store, Applied Energy 83 (2006) 749-773.

[10] A. Dodoo, L. Gustavsson, R. Sathre, Primary energy implications of ventilation heat recovery in residential buildings, Energy and Buildings 43 (2011) 1566-1572.

[11] X.Q. Zhai, Y.J. Dai, R.Z. Wang, Comparison of heating and natural ventilation in a solar house induced by two roof solar collectors, Applied Thermal Engineering 25 (2005) 741-757.

[12] O. Kizilkan, A. Sencan, S.A. Kalogirou, Thermoeconomic optimization of a $\mathrm{LiBr}$ absorption refrigeration system, Chemical Engineering and Processing 46 (2007) 1376-1384.

[13] P. Ahmadi, I. Dincer, M.A. Rosen, Exergo-environmental analysis of an integrated organic Rankine cycle for trigeneration, Energy Conversion and Management 64 (2012) 447-453

[14] P. Ahmadi, M.A. Rosen, I. Dincer, Multi-objective exergy-based optimization of a polygeneration energy system using an evolutionary algorithm, Energy 46 (2012) 21-31.

[15] G.Q. Zhang, L. Wang, L. Liu, Z. Wang, Thermoeconomic optimization of small size central air conditioner, Applied Thermal Engineering 24 (2004) 471-485.

[16] J. Xiong, H. Zhao, C. Zheng, Thermoeconomic cost analysis of a $600 \mathrm{MW}$ oxy-combustion pulverized-coal-fired power plant, International Journal of Greenhouse Gas Control 9 (2012) 469-483.

[17] Trading Economics, 2013, www.tradingeconomics.com/euro-area/inflation-cpi

[18] A. Fiksel, J.W. Thornton, S.A. Klein, W.A. Beckman, Development to the TRNSYS simulation program, ASME Journal of Solar Engineering 117 (1995) 123-127.

[19] The Solar Energy Laboratory, 2013, http://sel.me.wisc.edu/trnsys/index.html 